\title{
Effects of Mulligan's Mobilization with Movement on Talofibular Interval in Subjects with Chronic Ankle Instability
}

\author{
Eun-Kyung Koh'1, Do-Young Jung² \\ 'Department of Physical Therapy, Masan University, Masan; ${ }^{2}$ Department of Physical Therapy, Joongbu University, Geumsan, Korea
}

Purpose: This study was conducted to determine the effects of Mulligan's mobilization with movement (MWM) on changes in the talofibular interval in the sagittal plane in subjects with chronic ankle instability (CAl).

Methods: Sixteen subjects with chronic ankle instability participated in this study. The talofibular intervals were measured from US images, and the weight-bearing lunge test was used to assess dorsiflexion of the ankle joint. Each dependent variable were measured on the both affected side and sound side in three trials in pre- and post-MWM. Dependent variables were examined with a two-way mixeddesign analysis of variance (ANOVA). The two factors were side (sound side versus affected side) and intervention (pre- versus post-intervention). For post hoc analysis, paired t-tests were performed to compare the dependent variables. $A p<0.05$ was considered to indicate significance.

Results: Dorsiflexion and talofibular interval differed significantly pre- and post-intervention $(p<0.05)$. Post-hoc analysis revealed that the talofibular interval post-MWM was significantly less than that pre-MWM on the both the affected and sound side $(p<0.05)$. The ankle dorsiflexion in the post-MWM group was significantly greater than that in the pre-MWM group on the affected side and the sound side $(p<0.05)$.

Conclusion: The Mulligan's MWM decreased the talofibular interval in subjects with CAl. These findings suggest that the MWM technique can change the position of the talus relative to the fibular in the weight bearing position.

Keywords: Chronic ankle instability, Mulligan's mobilization with movement, Talofibular interval, Ultrasound

\section{서 론}

매년 스포츠 선수의 $20 \%$ 는 스포츠 손상을 받고 이 중 $14 \%$ 가 발목 손 상과 관련이 있다. 또한 발목 손상의 $80 \%$ 는 인대손상이다.! 발목 손상 의 유병률은 활동적인 일상생활과 스포츠 활동으로 인해 $40 \%$ 로 가 파르게 증가하였다. ${ }^{2,3}$ 이러한 인대 손상은 발목이 체중지지 시 강하 게 발바닥굽힘과 모음되었을 때 발생하며 스포츠 활동 중 점프 착지 시 또는 고르지 못한 지면에서 보행 시 발생할 수 있다. ${ }^{4}$ 발목 염좌 (ankle sprain)의 경우 20-40\%가 만성 발목 불안정성(chronic ankle instability)을 갖게 되고 반복된 불안정성 증후군, 역학적인 느슨함, 균 형 결핍 그리고 관절운동학적인 변화들이 발생한다. ${ }^{5}$
일반적으로 만성 발목 염좌를 가진 대상자들은 발목(talocrural joint)의 발등굽힘 제한이 있다. ${ }^{67}$ 반복적인 발목염좌와 발등굽힘 제 한의 관련성을 알아본 연구에서 89 목말뼈(talus)는 뒤쪽방향으로 미 끄러짐(glide)이 제한되고 목말뼈의 위치는 앞쪽 방향으로 이동하는 비정상적인 운동형상학적 변화가 있으며 910 먼쪽 종아리뼈(fibular)는 정강뼈(tibia)에 비해 앞쪽과 아래쪽 방향으로 아탈구되는 위치결함 이 있다고 보고하였다." 도수치료는 손상 후 관절가동범위 향상, 통 증 감소 그리고 기능 향상을 위해 사용된다.912 가장 일반적으로 목말 뼈를 앞-뒤 방향으로 하는 수동적인 부수적 관절 가동술(accessory joint motions), ${ }^{12-14}$ 빠른 속도의 수기법(manipulation) ${ }^{15,16}$ 그리고 멀리건 의 움직임을 동반한 가동술(Mulligan’s MWM) 기법이 ${ }^{9}$ 사용된다. 특
Received Sep 19, 2016 Revised Oct 31, 2016

Accepted Nov 2, 2016

Corresponding author Do-Young Jung

E-mail ptsports@joongbu.ac.kr

\section{Copylight @ 2016 The Korea Society of Physical Therapy}

This is an Open Access article distribute under the terms of the Creative Commons Attribution Non-commercial License (Http:// creativecommons.org/license/by-nc/4.0.) which permits unrestricted non-commercial use, distribution, and reproduction in any medium, provided the original work is properly cited.

Following are results of a study on the "Leades INdustry-university Cooperation" Project, supported by the Ministry of Education, Science \& Technology (MEST). 
히 멀리건의 움직임을 동반한 가동술의 기전은 발목염좌 이후 먼쪽 종아리뼈의 위치변화,17,18 그리고 목말뼈의 후방 미끄러짐 제한이 있 을 때9,17 적용될 수 있다. 관절이 손상 받거나 긴장되면 미세한 위치 결함이 발생하고 이는 움직임 제한 또는 통증이 나타난다. 이러한 위 치 결함은 방사선 판독 상 감지되지 않으며 촉진 시 잘 발견되지 않지 만 올바른 위치로 관절을 유지시키는 가동술이 시행되면 환자가 통 증없이 관절가동범위가 증가하고 여러 번의 가동술 적용은 지속적 으로 움직임을 향상시키게 된다. ${ }^{9}$

멀리건의 움직임을 동반한 가동술은 발목인대 손상 후 발등굽힘 향상을 목적으로 목말뼈에 대한 정강이뼈의 뒤-앞 방향 미끄러짐과 함께 능동적인 발등굽힘을 동시에 적용하는 접근방법으로 주로 체 중지지 상태로 적용한다. 멀리건의 움직임을 동반한 가동술의 효과 기전은 발목염좌 손상 후 먼쪽 종아리뼈의 위치결함을 재위치시켜 줌으로써 정상적인 발목관절의 운동형상학적 움직임을 회복시켜 발 등굽힘을 향상시키는 것이다." 따라서 멀리건의 움직임을 동반한 가 동술을 통한 역학적인 효과로 인해 아급성 발목 염좌 환자에게 통증 이 없는 발등굽힘 움직임의 빠른 회복을 일으킨다. 최근 외측 발목의 느슨함 검사는 진단의 정확도를 높이기 위해 초음파를 이용하여 목 말종아리 간격(talofibular interval)을 측정하여 시행된다.19,20 이전 연구 에서 발목손상이 있는 대상자에게 앞목말종아리인대(anterior talofibular ligament) 손상 검사를 위한 앞 끌림 검사(anterior drawer test) 시와 내전방향으로의 스트레스를 적용 시 초음파 도자를 앞목말종 아리 인대의 섬유방향에 위치시켜 인대의 길이를 측정하였다. 연구 결과 정상군에 비해 발목염좌 군에서 앞 끌림 검사 시 약 14 배 그리고 내전방향 스트레스 검사 시 약 3 배 정도의 길이 증가가 관찰되었다.19

현재까지 발목인대의 느슨함을 초음파를 통해 인대길이를 측정한 연구20,21는 있었으나 발목 관절에 움직임을 동반한 가동술 적용 후초 음파를 통해 목말종아리 관절 간격을 비교한 연구는 아직까지 없었 다. 본 연구의 목적은 만성발목불안정성 대상자에게 발목관절의 멀 리건의 움직임을 동반한 가동술이 즉각적으로 목말종아리관절 간 격과 발등굽힘 각도에 미치는 영향을 초음파를 통해 알아보고자 한 다. 본 연구의 가설은 다음과 같다. 첫 번째, 체중지지 자세에서 움직 임을 동반한 가동술 적용 후 목말종아리관절 간격이 움직임을 동반 한 가동술 적용 후 감소할 것이다. 두 번째, 체중지지 자세에서 발등굽 힘 정도가 움직임을 동반한 가동술 적용 후 증가할 것이다.

\section{연구 방법}

\section{1. 연구대상}

본 연구는 한쪽의 발목 불안정성을 가지고 있는 대상자로 지난 1년 동안 적어도 한번의 발목염좌 경험이 있으며 실험 참여 전 3-6개월 이
내에 적어도 한번의 재발성 발목 염좌 경험이 있는 대상자로 하였다. 또한 오른쪽과 왼쪽 발목의 체중지지 런지 검사에서 발등굽힘 각도 가 $2^{\circ}$ 이상차이가 있는 대상자들을 모집하였다.

발목의 병리학적 증상이 있거나 하지의 정형외과 수술 및 당뇨, 신 경병, 관절염이 있는 대상자 및 발목의 피부 또는 발톱 손상이 있는 경우를 제외하고 실험 참여에 대한 자발적 의사가 있는 16 명을 모집 하였고 32 개의 발목에서 실험을 실시하였다. 대상자의 일반적인 특징 으로 평균 나이는 22.7세(표준편차: 2.6세), 키는 $169.3 \mathrm{~cm}$ (표준편차: $10.5 \mathrm{~cm}$ ) 그리고 몸무게는 $60.2 \mathrm{~kg}$ (표준편차: $10.5 \mathrm{~kg}$ )이었다. 모든 대상 자들에게 실험 전 실험 동의서의 내용을 알려주고 연구 참여에 동의 를 얻은 후에 실시하였다. 전체적인 실험 설계에 대한 순서도(flow chart) 는 Figure 1에 제시하였다.

\section{2. 실험방법}

\section{1) 실험도구}

목말종아리관절 간격을 측정하기 위해 초음파 (logiq p6, GE Healthcare, Korea) 장비를 이용하였다. $12.0 \mathrm{MHz}, 38 \mathrm{~mm}$ 선형 도자를 이용 하여 주파수 대역에서 $4.0 \mathrm{~cm}$ 깊이로 스캐닝하였다. 발목 발등굽힘 정도를 측정하기 위해 $1 \mathrm{~mm}$ 간격의 눈금이 있는 줄자를 이용하였고 이 방법은 0.97 의 내적일치도(ICC)를 가지고 측정오류는 $0.5-0.6 \mathrm{~cm}$ 이 다. ${ }^{21}$ 멀리건의 움직임을 동반한 가동술을 위해 길이 $2.5 \mathrm{~m}$ 의 버클이 있는 도수견인 전용 벨트를 사용하였다. ${ }^{9}$

\section{2) 중재방법}

움직임을 동반한 가동술은 대상자가 편안한 자세로 테이블 위에서 서서 치료사가 적용하였다. 비탄성의 벨트를 대상자의 먼 쪽 다리에 두르고 치료사는 대상자의 다리 앞 쪽에 위치하였다. 치료사는 목말 뼈를 엄지와 검지 사이에 고정시키고 뒤로 미끄러짐이 일어나도록 하 는 동시에 정강이뼈가 앞으로 미끄러짐이 일어나도록 벨트를 통해 몸을 뒤로 기댄다(Figure 2). 또한 대상자는 무릎 위에 두 손을 올려 놓 고 발뒤꿈치가 바닥으로부터 떨어지지 않도록 통증의 첫 번째 개시 또는 움직임의 끝 범위까지 천천히 발등굽힘을 실시하였고 치료사는

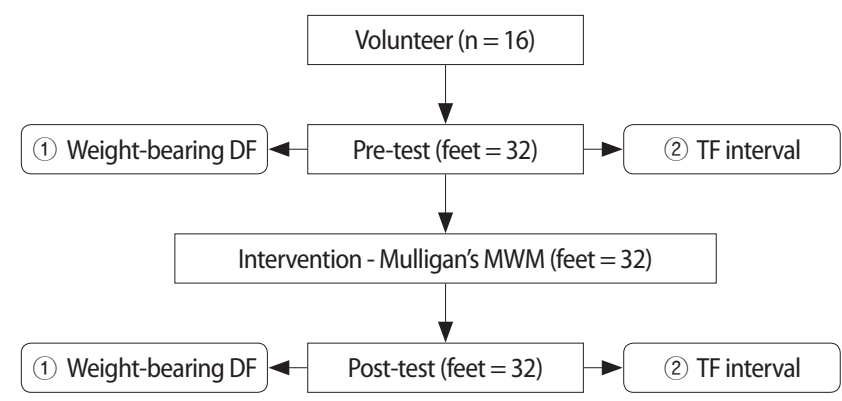

Figure 1. Flow chart of study design. 


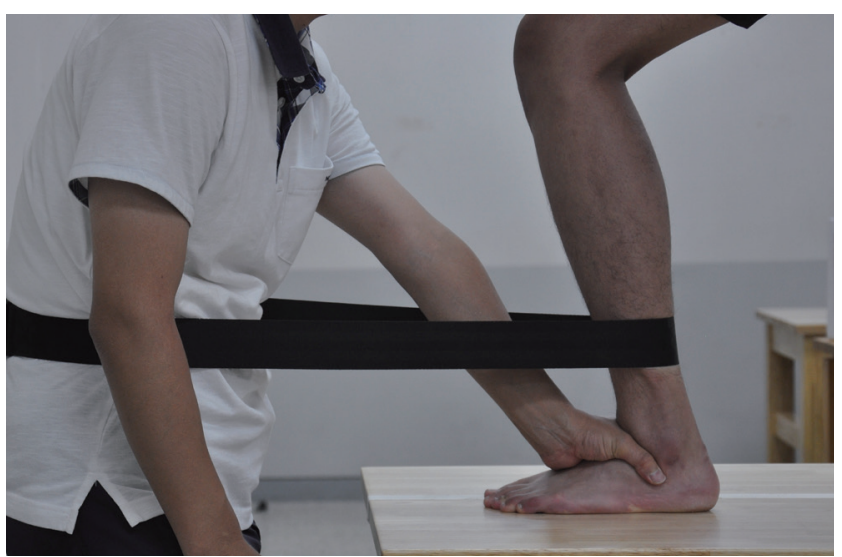

Figure 2. The Mulligan's mobilization with movement technique.

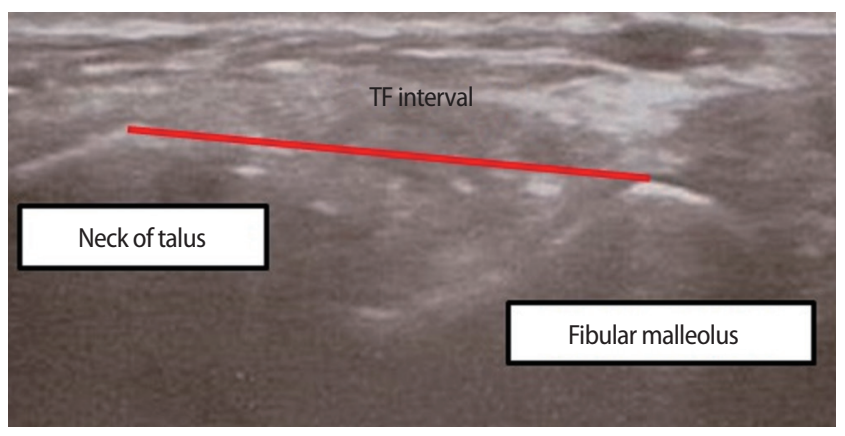

Figure 3. The ultrasound images of TF interval.

미끄러짐을 계속 유지하였다. 움직임 끝 범위에서 벨트가 정강이와 수직이 되도록 적용하였다. 다시 발바닥 굽힘 자세로 돌아가는 동안 에도 치료사는 손과 벨트를 이용하여 계속해서 미끄러짐을 유지하 였다. 1 세트마다 10 번을 반복하였고 세트 사이에 1 분 휴식을 주고 총 3세트를 실시하였다.22

\section{3) 측정방법}

대상자들은 움직임을 동반한 가동술 전·후에 초음파를 이용한 목말 종아리관절 간격, 체중지지 런지에서의 발등굽힘 길이를 측정하였 다. 대상자들은 움직임을 동반한 가동술 전. 후에 초음파 측정을 위 해 손상 측과 정상 측에서 $70 \mathrm{~cm}$ 높이의 테이블 위에서 바로 선 자세 에서 측정하였다. 검사자는 초음파 영상에 대한 경험이 있는 물리치 료사에 의해 실시하였다. 검사자는 가쪽복사(lateral malleolus)와 목 말뼈를 촉진하였고 초음파 겔을 사용한 후 초음파 도자를 외측 발목 을 따라 적용하였다. 검사자는 가쪽복사를 스크린의 오른쪽에 위치 하도록 하고 앞목말종아리 인대의 부착부위인 목말뼈의 외측 연골 과 목(neck)을 확인하였다. 영상의 최적화를 위하여 정강종아리 간격 을 수평 시야상을 가운데에 위치하도록 한 후 검사자는 영상을 저장 하고 도자를 제거하였다. 대상자가 서 있는 자세에서 세 번씩 발목의

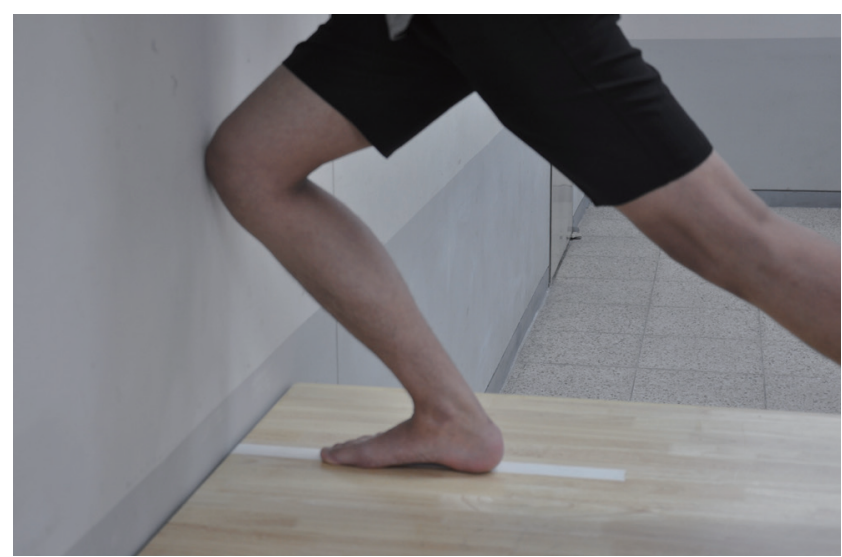

Figure 4. Measurement of weight-bearing dorsiflexion.

영상을 저장하였다. 목말종아리 간격은 조작적 정의로 앞 목말정강 종아리 인대에 평행하게 촬영된 초음파 영상에서의 목말뼈와 정강 이뼈 표식자 사이의 앞-뒤 거리이다(Figure 3). 검사자는 한 영상 당 한 번 측정하였다. 검사자는 초음파 장비의 내장된 디지털 캘리퍼를 이 용하여 한 영상 당 한 번 측정하였다.

체중지지에서의 발목 발등굽힘은 체중지지 런지자세에서 치료 전·후에 세 번 반복 측정하였다(Figure 4). 검사는 서서 두 번째 발가 락, 발뒤꿈치 그리고 무릎 중심이 벽에 수직면에 위치하도록 시행되 었다. 대상자는 발뒤꿈치가 바닥으로부터 고정되어 들리지 않도록 하면서 무릎 앞쪽이 벽에 닿고 최대로 발등굽힘이 되도록 런지를 앞쪽 으로 하였다. 바닥에 놓여있는 테이프에 두 번째 발가락 끝에 표시를 하여 벽으로터의 거리를 간접적인 발등굽힘 정도로 측정하였다.921,22

\section{3) 통계방법}

중재 전·후 그리고 정상 측과 손상 측에 대한 대한 독립변수들의 유 의한 차이를 알아보기 위해 혼합 이요인 분산분석(two way-mixed ANOVA)을 사용하였다. 사후검정으로 치료 전·후의 짝비교 t-검정 을 실시하였다. 유의수준은 0.05 로 하였으며 통계 프로그램은 SPSS version 17.0 (SPSS Inc., Chicago, IL, USA)을 이용하여 통계 처리하였다.

\section{결 과}

이요인 분산분석 결과 체중지지 런지에서의 발등굽힘 정도와 목말종 아리관절 간격은 중재 전과 후에 유의한 차이가 있었으며 $(\mathrm{p}<0.05)$, 손상 측과 정상 측 사이에는 유의한 차이가 없었다 $(\mathrm{p}>0.05)$ (Table 1). 사후분석으로 정상 측과 손상 측 모두 체중지지 런지에서의 발등굽 힘 정도와 목말종아리 간격이 중재 전. 후에 유의한 차이가 있었다 $(\mathrm{p}<0.05)($ Table 2$)$. 
Table 1. Two way mixed-design analysis of variance for variables in interventions and sides

\begin{tabular}{llcl}
\hline Variables & \multicolumn{1}{c}{ Factors } & $\mathrm{F}$ & $\mathrm{p}$ \\
\hline WB dorsiflexion $(\mathrm{cm})$ & Intervention & 52.17 & $0.00^{*}$ \\
& Side & 0.18 & 0.67 \\
& Intervention $\times$ side & 0.60 & 0.44 \\
TF interval (mm) & Intervention & 60.02 & $0.00^{\star}$ \\
& Side & 0.07 & 0.79 \\
& Intervention x side & 7.64 & $0.01^{\star}$ \\
\hline
\end{tabular}

WB: weight bearing, TF: talofibular. ${ }^{*} p<0.05$.

\section{고 찰}

본 연구에서는 만성 발목 불안정성이 있는 대상자들에게 멀리건의 움직임을 동반한 가동술을 적용 시 목말뼈와 종아리뼈사이 간격의 변화를 알아보고자 하였다. 연구결과, 목말종아리 간격이 중재 후에 건 측과 손상 측에서 각각 $1.0 \mathrm{~mm}$ 와 $2.1 \mathrm{~mm}$ 유의하게 감소하였다. 멀 리건의 움직임을 동반한 가동술은 발목염좌 환자를 대상으로 발목 관절의 발등굽힘을 향상시키기 위해 체중지지 자세에서 능동적인 발 목의 발등굽힘과 함께 목말뼈에 대해 정강이뼈를 앞쪽으로 미끄러 짐 혹은 정강이뼈에 대해 목말뼈를 뒤쪽으로 미끄러짐을 적용하는 기법으로 정상적인 발목관절의 운동형상학적 움직임을 회복하는 목 적으로 사용된다. ${ }^{9}$ 비록 이전 연구에서는 목말종아리 간격을 앞목말 종아리인대 손상 검사를 위한 앞끌기 검사 시 인대의 느슨함 정도를 측정하기 위해 처음으로 사용되었지만 본 연구에서는 목말뼈와 종 아리뼈의 상대적인 위치를 알아보기 위해서 사용되었다. 최근 연구 에서 초음파를 이용해서 능동적인 발목의 움직임 후에 목말종아리 간격을 측정한 결과 대조군보다 만성 발목 불안정성군이 평균 1.8 $\mathrm{mm}$ 더 길었다. ${ }^{23}$ 이러한 결과는 Wikstrom와 Hubbard (2010)의 연구결 과와 유사한 결과를 보여주었다. 이들 또한 방사선 상의 정강이뼈에 비해 목말뼈의 위치가 만성 발목 불안정성군이 짝짓기한 대조군에 비해 $1.04 \mathrm{~mm}$ 앞으로의 위치결함이 있다고 보고하였다. ${ }^{24}$ 따라서 이 전 연구를 바탕으로 본 연구에서는 멀리건의 움직임을 동반한 가동 술이 기립 시 목말뼈와 종아리뼈 사이의 간격인 목말종아리 간격이 감소할 것이다라는 가설을 설정하게 되었다.

이전 연구들에서 목말종아리 간격은 앞목말종아리인대 손상 검 사를 위한 앞끌기 검사 시 인대의 느슨함 정도를 측정하기 위해 사용 되었다. Fujii 등25은 사체연구에서 앞끌기 검사 시 느슨함에서 앞목말 종아리인대의 절단 전·후에 평균 2.0-3.9 mm 증가하였고 Johnson과 Markolf'26는 30 개의 사체연구에서 $3.7 \mathrm{~mm}$ 증가가 있었다고 보고하였 다. Croy 등 ${ }^{19}$ 은 정강종아리 관절의 초음파를 이용하여 정강발목인대 의 길이변화율을 알아보았고 그 결과 전방 발목 끌림 스트레스 시 발
Table 2. Comparison of variables between pre- and post-intervention

\begin{tabular}{llccc}
\hline Variables & Side & $\begin{array}{c}\text { Pre-interven- } \\
\text { tion }\end{array}$ & $\begin{array}{c}\text { Post-interven- } \\
\text { tion }\end{array}$ & $p$ \\
\hline WB dorsiflexion $(\mathrm{cm})$ & Sound & $12.7 \pm 3.7$ & $14.2 \pm 4.0$ & $<0.001 *$ \\
& Affected & $11.9 \pm 3.6$ & $13.8 \pm 3.7$ & $<0.001 *$ \\
\multirow{2}{*}{ TF interval $(\mathrm{mm})$} & Sound & $22.6 \pm 3.6$ & $21.6 \pm 3.8$ & $<0.001 *$ \\
& Affected & $23.5 \pm 3.5$ & $21.4 \pm 3.6$ & $<0.001 *$ \\
\hline
\end{tabular}

Mean \pm SD: mean \pm standard deviation, WB: weight bearing, TF: talofibular. $* p<0.05$.

목염좌 후 회복했던 대상자와 만성 발목염좌 대상자들은 대조군에 비해 목말종아리 간격이 각각 $2.2 \mathrm{~mm}$ 와 $2.9 \mathrm{~mm}$ 차이가 있었다. 따라 서 이전 연구들에서는 인대 길이 증가와 인대 손상은 앞-뒤 불안정성 을 초래할 수 있다고 하였다. 이전 연구들을 근거로 본 연구에서는 정 상 측보다중재 후 목말종아리 간격이 건측에 비해 2 배 감소가 있었다 는 결과를 통해 관절의 불안정성이 멀리건의 움직임을 동반한 가동 술 적용 후 정강뼈에 대해서 목말뼈가 뒤쪽으로 재위치시킴으로써 목말종아리 간격을 감소시켜 안정적으로 되었다는 것을 의미한다.

본 연구에서는 멀리건의 움직임을 동반한 가동술 전·후에 초음파 상 목말뼈와 종아리뼈 사이의 간격이 가까워지는지를 알아보았을 뿐만 아니라 발등굽힘 정도를 비교하였다. 발등굽힘 각도와 목말뼈 의 뒤쪽 굴림의 제한이 있는 발목손상 대상자에게 멀리건의 움직임 을 동반한 가동술 적용이 목말뼈의 위치와 발등굽힘에 미치는 영향을 알아본 이전 연구에서 ${ }^{9}$ 목말뼈의 초기 각도는 $2.3^{\circ}$ 에서 중재 후 $4.0^{\circ}$ 로 목말뼈 후방 미끄러짐이 $1.7^{\circ}$ 증가하였고 체중지지 런지에서 발등굽 힘 정도가 $4.2 \mathrm{~cm}$ 에서 중재 후 $4.8 \mathrm{~cm}$ 로 발등굽힘이 $0.6 \mathrm{~cm}$ 증가하였으 며 목말뼈의 뒤쪽 미끄러짐이 발등굽힘과의 상관성은 0.88 로 상관관 계가 매우 높았다. 비록 본 연구와 직접적으로 비교하기는 어려우나 발목 염좌 후 종아리뼈의 원위부의 뒤쪽으로의 이동과 목말뼈의 앞 쪽으로의 이동으로 인한 목말종아리 간격의 증가가 움직임을 동반한 관절가동술 후 목말뼈가 뒤쪽으로 재위치되면서 간격이 좁아진 결 과를 뒷받침할 수 있다. 본 연구에서는 멀리건의 움직임을 동반한 가 동술 전·후에 발목관절의 발등굽힘 정도가 손상 측에서는 각각 11.9 $\mathrm{cm}$ 와 $13.8 \mathrm{~cm}$ 로 $1.9 \mathrm{~cm}$ 증가하였고 건측에서는 $12.7 \mathrm{~cm}$ 와 $14.2 \mathrm{~cm}$ 로 $1.5 \mathrm{~cm}$ 증가하였다. Marron-Gomez 등의 연구에서 움직임을 동반한 관절가동술을 만성 발목 염좌가 있는 대상자에게 적용하였고 그 결 과 $9.8 \mathrm{~cm}$ 에서 $11.5 \mathrm{~cm}$ 로 $1.7 \mathrm{~cm}$ 가 증가하였다.22 본 연구의 손상 측에 서의 $1.9 \mathrm{~cm}$ 의 증가는 Marron-Gomez의 연구 결과와 거의 일치하였 다. 그러나 기존 연구들은 단지 관절가동술 적용이 발목 발등굽힘 각 도를 증가시켰다는 기전을 염좌가 반복되는 대상자에서 목말뼈가 앞 쪽으로 이동으로 인한 뒤쪽으로 목말뼈 가동의 제한 즉, 위치적인 결 함을 재위치시킴으로써 관절 운동학에 영향을 줄 수 있었다고 설명 하고 추측하였을 뿐 확인하지는 못했다.19,22 본 연구를 통해 치료사의 
손과 벨트를 이용해 목말뼈를 뒤로 종아리뼈를 앞으로 미끄러지게 함으로써 목말종아리 간격을 감소시켰으며 이를 통해 체중지지에서 의 움직임이 있는 관절가동술을 통해 발목관절의 발등굽힘 시 관절 형상학적인 변화를 일으켜 주변관절낭을 늘리고 부수적인 관절 움 직임이 향상된다 22 는 이론을 뒷받침할 수 있다고 사료된다. 본 연구에 서의 제한점은 목말종아리 간격을 정적인 자세인 선 자세에서 측정 하였다는 것이다. 실질적으로 발목관절의 발등굽힘이 일어났을 때의 목말종아리 간격의 측정을 통해 실시간의 목말뼈가 뒤로 미끄러지는 것을 측정해야 한다. 하지만 장비의 정확도와 장비 자체의 제약 때문 에 정적인 자세에서 측정할 수 밖에 없는 실정이었다. 다른 제한점으 로 발목관절의 불안정성은 손상 시 부상 정도, 부상횟수, 부상 후 처 치에 따른 회복정도에 따라 목말뼈의 위치적 결함에 미치는 영향이 다를 것이므로 만성 발목불안정성을 가지고 있는 다양한 대상자들 에게 움직임을 동반한 관절가동술을 적용했을 때 효과가 다양할 수 있을 것이다. 따라서 향후 연구에서는 대상자의 선정조건을 좀더 구 체적으로 하여 본 실험을 할 필요가 있을 것이다. 본 연구를 통해 임 상가들은 발목재활 시 관절운동학적 변화를 하나의 요소로 주목하 여 치료할 필요가 있으며 멀리건의 움직임을 동반한 가동술이 관절 운동학적 변화를 일으켜 관절 안정성을 증가시키고 기능적인 활동 시 발등굽힘에 영향을 주므로 적극적이고 효과적인 치료방법으로 추천한다. 향후 연구에서는 장기적인 멀리건의 움직임을 동반한 관절 가동술 적용이 발등굽힘 시 실시간 목말뼈의 뒤쪽 미끄러짐 정도와 기능적인 활동 시 발등굽힘에 대한 효과를 알아보아야할 것이다.

\section{참고문헌}

1. Tegner Y, Lysholm J. Rating systems in the evaluation of knee ligament injuries. Clin Orthop Related Res. 1985;198:43-9.

2. Maffulli N, Longo UG, Gougoulias N et al. Sport injuries: a review of outcomes. 2011;97(1):47-80.

3. Kim JH, Uhm YH. Effect of ankle stabilization training using biofeedback on balance ability and lower limb muscle activity in football players with functional ankle instability. J Kor Phys Ther. 2016;28(3):189-94.

4. Choi HS, Shin WS, Shim JK et al. The relationship between functional movement screen and ankle dysfunctions with chronic ankle instability. J Kor Phys Ther. 2014;26(6):459-63.

5. Hertel J. Functional anatomy, pathomechanics, and pathophysiology of lateral ankle instability. J Athl Train. 2002;37(4):364-75.

6. Drewes LK, McKeon PO, Kerrigan DC et al. Dorsiflexion deficit during jogging with chronic ankle instability. J Sci Med Sport. 2009;12(6):685-7.

7. Hoch MC, Staton GS, Medina M et al. Dorsiflexion and dynamic postural control deficits are present in those with chronic ankle instability. J Sci Med Sport. 2012;15(6):574-9.

8. Koo CH, Lee IH, Park KL et al. The effect of passive joint mobilization and massage on subacute lateral ankle ligament injuries. J Kor Phys Ther. 2005;17(4):457-67.
9. Vicenzino B, Branjerdporn M, Teys P et al. Initial changes in posterior talar glide and dorsiflexion of the ankle after mobilization with movement in individuals with recurrent ankle sprain. J Orthop Sports Phys Ther. 2006;36(7):464-71.

10. Wikstrom EA, Hubbard TJ. Talar positional fault in persons with chronic ankle instability. Arch Phys Med Rehabil. 2010;91(8):1267-71.

11. Hubbard TJ, Hertel J, Sherbondy P. Fibular position in individuals with self-reported chronic ankle instability. J Orthop Sports Phys Ther. 2006; 36(1):3-9.

12. Green T, Refshauge K, Crosbie J et al. A randomized controlled trial of a passive accessory joint mobilization on acute ankle inversion sprains. Phys Ther. 2001;81(4):984-94.

13. De Souza MV, Venturini C, Teixeira LM et al. Force-displacement relationships during anteroposterior mobilization of the ankle joint. J Manipulative Physiol Ther. 2008;31(4):285-92.

14. Venturini C, Penedo MM, Peixoto GH et al. Study of the force applied during anteroposterior articular mobilization of the talus and its effect on the dorsiflexion range of motion. J Manipulative Physiol Ther. 2008; 31(4):285-92.

15. Andersen S, Fryer GA, McLaughlin PA. The effect of talo-crural joint manipulation on range of motion at the ankle joint in subjects with a history of ankle injury. Australas Chiropr Osteopathy. 2003;11(2):57-62.

16. Fryer GA, Mudge JM, McLaughlin PA. The effect of talocrural joint manipulation on range of motion at the ankle. J Manipulative Physiol Ther. 2002;25(6):384-90.

17. Collins n, Teys P, Vicenzino b. The initial effects of a Mulligan's mobilization with movement technique on dorsiflexion and pain in subacute ankle sprains. Man Ther. 2004;9(2):77-82.

18. Hubbard TJ, Hertel J, Sherbondy P. Fibular position in individuals with self-reported chronic ankle instability. J Orthop Sports Phys Ther. 2006; 36(1):3-9.

19. Croy T, Saliba S, Saliba E et al. Differences in lateral ankle laxity measured via stress ultrasonography in individuals with chronic ankle instability, ankle sprain copers, and healthy individuals. J Orthop Sports Phys Ther. 2012;42(7):593-600.

20. Croy T, Koppenhaver S, Saliba S et al. Anterior talocrural joint laxity: diagnostic accuracy of the anterior drawer test of the ankle. J Orthop Sports Phys Ther. 2013;43(12):911-9.

21. Bennell K, Talbot R, Wajswelner $\mathrm{H}$ et al. Intra-rater and inter-rater reliability of a weight-bearing lunge measure of ankle dorsiflexion. Aust J Physiother, 1998;44(3):175-80.

22. Marrón-Gómez D, Rodríguez-Fernández ÁL, Martín-Urrialde JA. The effect of two mobilization techniques on dorsiflexion in people with chronic ankle instability. Phys Ther Sport. 2015;16(1):10-5.

23. Croy T, Cosby NL, Hertel J. Active ankle motion may result in changes to the talofibular interval in individuals with chronic ankle instability and ankle sprain copers: a preliminary study. J Man Manip Ther. 2013; 21(3):127-33.

24. Wikstrom EA, Hubbard TJ. Talar positional fault in persons with chronic ankle instability. Arch Phys Med Rehabil. 2010;91(8):1267-71.

25. Fujii T, Luo ZP, Kitaoka et al. The manual stress test may not be sufficient to differentiate ankle ligament injuries. Clin Biomech. 2000;15(8):619-23.

26. Johnson EE, Markolf KL. The contribution of the anterior talofibular ligament to ankle laxity. J Bone Joint Surg Am. 1983;65(1):81-8. 